\title{
Photothermal-modulated drug delivery and magnetic relaxation based on collagen/ poly $(\gamma$-glutamic acid) hydrogel
}

This article was published in the following Dove Press journal:

International Journal of Nanomedicine

31 March 2017

Number of times this article has been viewed

\author{
Sun-Hee Chol,* \\ Ahreum Kim ${ }^{1, *}$ \\ Woojung Shin ${ }^{2}$ \\ Min Beom Heo' \\ Hyun Jong Noh' \\ Kwan Soo Hong ${ }^{3,4}$ \\ Jee-Hyun $\mathrm{Cho}^{3,4}$ \\ Yong Taik Lim ${ }^{1,2}$ \\ 'SKKU Advanced Institute of \\ Nanotechnology (SAINT), ${ }^{2}$ School of \\ Chemical Engineering, Sungkyunkwan \\ University, Suwon, ${ }^{3}$ Bioimaging \\ Research Team, Korea Basic Science \\ Institute, Cheongju, ${ }^{4}$ Immunotherapy \\ Convergence Research Center, Korea \\ Research Institute of Bioscience and \\ Biotechnology, Daejeon, Republic \\ of Korea \\ *These authors contributed equally \\ to this work
}

\begin{abstract}
Injectable and stimuli-responsive hydrogels have attracted attention in molecular imaging and drug delivery because encapsulated diagnostic or therapeutic components in the hydrogel can be used to image or change the microenvironment of the injection site by controlling various stimuli such as enzymes, temperature, $\mathrm{pH}$, and photonic energy. In this study, we developed a novel injectable and photoresponsive composite hydrogel composed of anticancer drugs, imaging contrast agents, bio-derived collagen, and multifaceted anionic polypeptide, poly ( $\gamma$-glutamic acid) ( $\gamma$-PGA). By the introduction of $\gamma$-PGA, the intrinsic temperature-dependent phase transition behavior of collagen was modified to a low viscous sol state at room temperature and nonflowing gel state around body temperature. The modified temperature-dependent phase transition behavior of collagen/ $\gamma$-PGA hydrogels was also evaluated after loading of near-infrared (NIR) fluorophore, indocyanine green (ICG), which could transform absorbed NIR photonic energy into thermal energy. By taking advantage of the abundant carboxylate groups in $\gamma$-PGA, cationic-charged doxorubicin (Dox) and hydrophobic $\mathrm{MnFe}_{2} \mathrm{O}_{4}$ magnetic nanoparticles were also incorporated successfully into the collagen $/ \gamma$-PGA hydrogels. By illumination of NIR light on the collagen $/ \gamma$-PGA/Dox/ICG/ $\mathrm{MnFe}_{2} \mathrm{O}_{4}$ hydrogels, the release kinetics of Dox and magnetic relaxation of $\mathrm{MnFe}_{2} \mathrm{O}_{4}$ nanoparticles could be modulated. The experimental results suggest that the novel injectable and NIR-responsive collagen $\gamma$-PGA hydrogels developed in this study can be used as a theranostic platform after loading of various molecular imaging probes and therapeutic components.
\end{abstract}

Keywords: hydrogel, photothermal, near-infrared, drug delivery, magnetic nanoparticles

\section{Introduction}

The design and fabrication of multifunctional hydrogels are important issues in both the pharmaceutical and medical research fields because of their high potential for use in molecular imaging, drug delivery, and tissue engineering. ${ }^{1-9}$ By modulating the chemical or physical interactions between natural and/or synthetic polymeric materials, various types of hydrogels have been developed. ${ }^{10-15}$ Although the chemical gelation strategy using synthetic polymers shows advantages, such as the systematic control of molecular structure and resultant hydrogel properties, toxicity issues still limit their wide adoption in clinical fields. ${ }^{10,12,13}$ In contrast, physical hydrogels based on natural polymers exhibit excellent biocompatibility and have been used in humans for many years. ${ }^{11,12,14,15}$ However, few resources are available for modulation of the physicochemical properties of natural polymer-based hydrogels adapted to their target applications. ${ }^{11,14,15}$ Collagens are one of the major hydrogel component materials studied as drug delivery carriers and scaffolds for cell therapy. ${ }^{16-20}$ They are the major structural proteins of most connective 
tissues such as skin, bone, and tendons, providing structural integrity to the tissues. Because of their triple helix structure and ability to interact with water molecules, collagens showed interesting temperature-dependent gelation behaviors. The fibril structures were well-dispersed in aqueous solution at low temperature, while they formed a gel at elevated temperature via the aggregation of the fibril structure. ${ }^{16,17}$ To improve the weak mechanical properties and rapid degradation characteristics of collagen, high-concentration collagen solutions and cross-linked collagen gels are used in various applications. ${ }^{21,22}$ However, the high viscosity and gelation properties of highly concentrated collagen solutions at room temperature limit their use. Furthermore, there are few available chemical moieties of collagen backbone structured by glycine, proline, and hydroxyproline, limiting the robust incorporation of various multifunctional components such as chemical drugs and nanoparticles. ${ }^{21,23}$
In this study, injectable and multifunctional hydrogels were developed by modulating the intrinsic thermoresponsive gelation behavior of collagen with poly $(\gamma$-glutamic acid) ( $\gamma$-PGA), a multifaceted anionic polymer electrolyte. $\gamma$-PGA is a hydrophilic anionic polymer that is biodegradable and has attracted interest as a promising biomaterial for a variety of applications in medicine, cosmetics, and the food industry. ${ }^{24-26}$ Here, we found that $\gamma$-PGA material has a robust chemical moiety that can be used to develop multifunctional collagen $/ \gamma$-PGA hydrogels based on the following multifaceted properties (Scheme 1): 1) through the introduction of $\gamma$-PGA, the intrinsic phase transition behavior of highconcentration collagen solutions could be modified to a low viscous sol state at room temperature and nonflowing gel state at approximately body temperature (ie, injectable hydrogel); 2 ) based on the anionic character of $\gamma$-PGA, cationic-charged Doxorubicin (Dox) was successfully incorporated into the

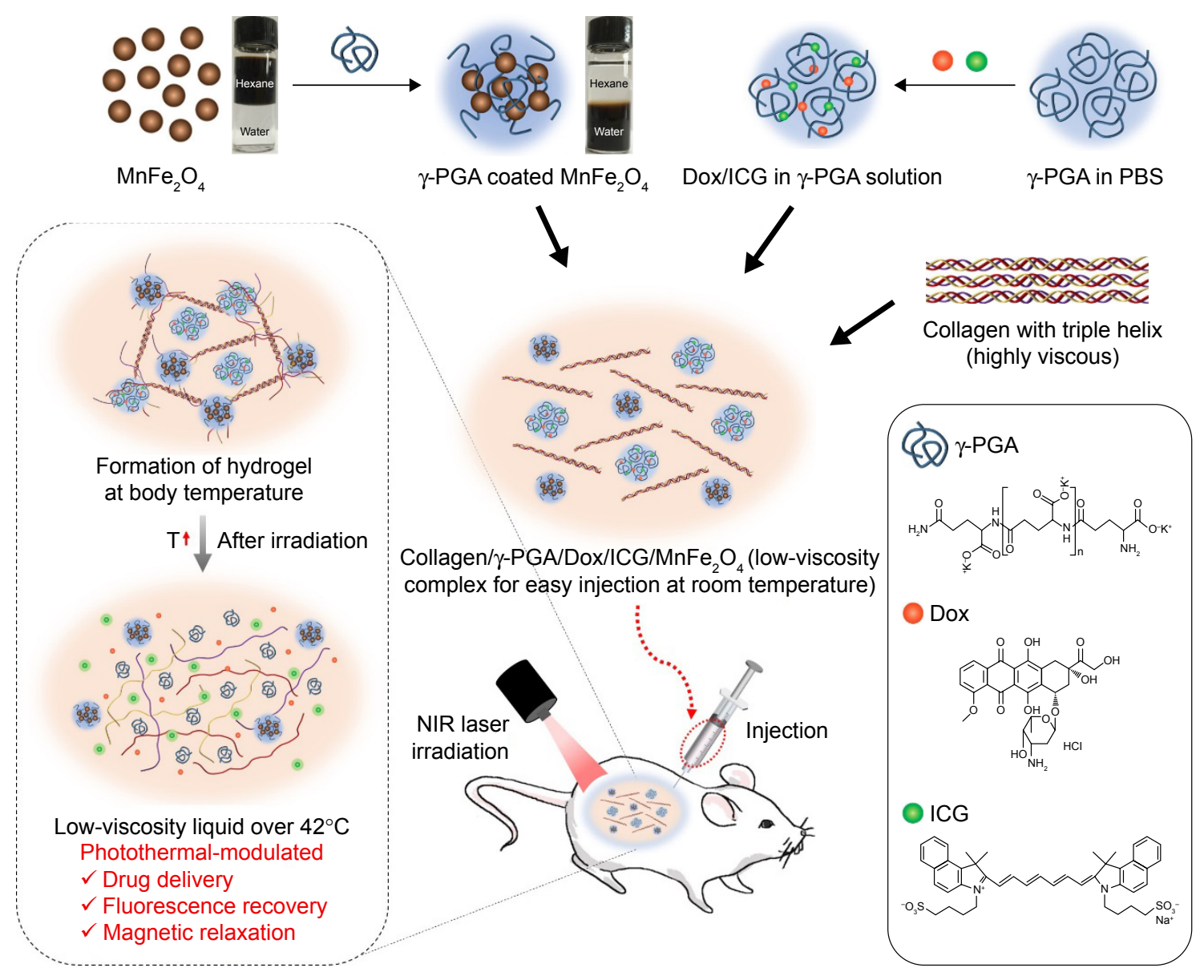

Scheme I Schematic illustrations of the fabrication and photothermal-modulating strategy of injectable collagen/ $\gamma-\mathrm{PGA}_{\mathrm{D}} \mathrm{Dox} / \mathrm{ICG} / \mathrm{MnFe}_{2} \mathrm{O}_{4}$ hydrogels.

Notes: Collagen $/ \gamma$-PGA hydrogels containing $\mathrm{MnFe}_{2} \mathrm{O}_{4}$, Dox, and ICG (collagen $/ \gamma$-PGA/Dox/ICG/MnFe $\mathrm{O}_{4}$ hydrogels) were fabricated by mixing collagen solution and $\gamma$-PGA solution containing $\gamma$-PGA-coated $\mathrm{MnFe}_{2} \mathrm{O}_{4}$, Dox, and ICG. Collagen $/ \gamma$-PGA/Dox/ICG/MnFe $\mathrm{O}_{4}$ complexes were easy to inject using a syringe and formed hydrogels after injection into the body. Following hydrogel formation, collagen $/ \gamma-\mathrm{PGA} / \mathrm{Dox} / \mathrm{ICG} / \mathrm{MnFe}_{2} \mathrm{O}_{4}$ hydrogels were disrupted after irradiation with an NIR laser. This resulted in the release of Dox, ICG, and $\mathrm{MnFe}_{2} \mathrm{O}_{4}$ from the hydrogels.

Abbreviations: $\gamma$-PGA, poly $(\gamma$-glutamic acid); Dox, doxorubicin; ICG, indocyanine green; NIR, near-infrared; PBS, phosphate-buffered saline; T, temperature. 
collagen $/ \gamma$-PGA hydrogels; 3 ) by taking advantage of the abundant carboxylate groups in $\gamma$-PGA, the hydrophobic surface of $\mathrm{MnFe}_{2} \mathrm{O}_{4}$ nanoparticles could be easily modified with hydrophilic $\gamma$-PGA and successfully incorporated into collagen $/ \gamma$-PGA hydrogels. To develop collagen $/ \gamma$-PGA hydrogels with photothermal-modulation properties, the hydrogels were also loaded with near-infrared (NIR) fluorophore, indocyanine green (ICG), which could transform absorbed NIR photonic energy into thermal energy. Finally, we showed that the hydrogels could be used for photothermally modulated anticancer drug delivery as a therapeutic intervention as well as for magnetic relaxation as a diagnostic strategy (Scheme 1).

\section{Materials and methods Materials}

$\gamma$-PGA $\left(\mathrm{K}^{+}\right.$form; $\mathrm{Mw}=500 \mathrm{kDa}$ ) was kindly provided by BioLeaders Corporation (Daejeon, Republic of Korea). Collagen (type 1) was purchased from Bioland Corporation (Cheonan, Republic of Korea). Clinical-grade ICG was purchased from Dong In Dang Pharm (Siheung, Republic of Korea). Dox ( $\mathrm{HCl}$ form) was obtained from ChemieTek (Indianapolis, IN, USA). Granulocyte macrophage colonystimulating factor (GM-CSF) was purchased from R\&D Systems (Minneapolis, MN, USA). To synthesize magnetic nanoparticles $\left(\mathrm{MnFe}_{2} \mathrm{O}_{4}\right)$, iron (III) acetylacetonate, manganese (II) acetylacetonate, 1,2-hexadecanediol, oleic acid, oleylamine, and 1-octadecene were purchased from SigmaAldrich (St Louis, MO, USA).

\section{Methods}

Preparation and characterization of collagen $/ \gamma-$ PGA hydrogels

A $2 \%(\mathrm{w} / \mathrm{v})$ collagen solution was prepared by mixing collagen into phosphate-buffered saline (PBS) solution with mild shaking at $4^{\circ} \mathrm{C}$ for $5 \mathrm{~min}$. The solution was stored at $4^{\circ} \mathrm{C}$ for 2 days with 5 min mild shaking every $8 \mathrm{~h}$. A $2 \%$ (w/v) $\gamma$-PGA solution was prepared by dissolving $\gamma$-PGA into PBS with a rotator mixer. Collagen $/ \gamma$-PGA solution was prepared by mixing the above collagen and $\gamma$-PGA solution (volume ratio $4: 1$ ). The final concentrations of collagen and $\gamma$-PGA were $1.6 \%$ and $0.4 \%$, respectively. The rheological properties of only collagen and collagen $/ \gamma$-PGA hydrogels were studied using a Bohlin Gemini II (Malvern Instruments Ltd., Malvern, UK). A parallel geometry plate (with a 25-mm diameter and 1-mm gap) was used for all measurement. To investigate the effect of urea on collagen $/ \gamma$-PGA hydrogels, $500 \mu \mathrm{L}$ of mixed collagen $/ \gamma$-PGA solution was loaded into a
4-mL glass vial and incubated at $37^{\circ} \mathrm{C}$ for $30 \mathrm{~min}$ to formulate the hydrogel. The same volume of urea, dissolved in PBS, was added on top of the hydrogel, and the stability of hydrogel was observed over time. For scanning electron microscopy (SEM) observation, a sample of collagen $/ \gamma$-PGA hydrogel was lyophilized. Thereafter, a broken cross-section of the sample was sputtered with platinum and examined by field emission SEM (JSM-7000F, JEOL Ltd., Tokyo, Japan).

\section{In vivo study in mice}

$\mathrm{BALB} / \mathrm{c}$ nude mice (female, 6-7 weeks old) were purchased from Orient Bio (Seongnam, Republic of Korea) and maintained under pathogen-free conditions. The animal study was reviewed and approved by the institutional animal care and use committee of Sungkyunkwan University School of Medicine, which is an accredited facility by the Association for Assessment and Accreditation of Laboratory Animal Care International and abides by the Institute of Laboratory Animal Resources guide.

\section{Photothermal effect on collagen/ $\gamma$-PGA/ICG hydrogels}

To investigate the photothermal effect on collagen $/ \gamma$-PGA hydrogel, ICG $(10-100 \mu \mathrm{g})$ as an NIR absorbing dye was added to the collagen $/ \gamma$-PGA solutions $(1 \mathrm{~mL})$ and the solutions were then incubated at $37^{\circ} \mathrm{C}$ for $30 \mathrm{~min}$ to formulate hydrogel. Next, an NIR laser (760 nm laser diode, Photodigm, Richardson, TX, USA) was used to illuminate the collagen $/ \gamma$-PGA/ICG hydrogel $\left(0.47 \mathrm{~W} / \mathrm{cm}^{2}, 3 \mathrm{~min}\right)$. For NIR fluorescence imaging, collagen $/ \gamma-\mathrm{PGA} / \mathrm{ICG}$ hydrogel was placed in a chamber sealed from light and connected to a cold charge-coupled device camera (Orca ERG; Hamamatsu Photonics, Hamamatsu City, Japan). NIR images of ICG in the collagen $/ \gamma$-PGA/ICG hydrogel were acquired using a 760-nm LED light as the excitation light source and an $845 / 55$ emission filter. To confirm the temperature increase in collagen $/ \gamma$-PGA/ICG hydrogel after irradiation with an NIR laser $\left(0.63 \mathrm{~W} / \mathrm{cm}^{2}, 5 \mathrm{~min}\right)$, the change in temperature of the collagen $/ \gamma-\mathrm{PGA} / \mathrm{ICG}$ hydrogel in vivo was measured using a thermal imaging camera (FLIR TG165, FLIR Instruments, Wilsonville, OR, USA).

\section{Photothermal-modulated release analysis of Dox and GM-CSF from collagen $/ \gamma$-PGA hydrogels} First, $1 \mathrm{mg}$ of $500 \mathrm{kDa} \gamma$-PGA and $1 \mathrm{mg}$ of Dox ( $\mathrm{HCl}$ form) were dissolved in deionized water at $1 \mathrm{mg} / \mathrm{mL}$. Both solutions were mixed under agitation for $1 \mathrm{~h}$ at room temperature and freeze-dried. Dried samples were dissolved in $50 \mu \mathrm{L}$ 
PBS, and then $200 \mu \mathrm{L}$ of $20 \mathrm{mg} / \mathrm{mL}$ collagen solution was added, followed by vigorous vortexing for $1 \mathrm{~min}$. For GM$\mathrm{CSF}, 1 \mathrm{mg}$ of $500 \mathrm{kDa} \gamma$-PGA was dissolved in $25 \mu \mathrm{L}$ PBS and $500 \mathrm{ng}$ of GM-CSF was dissolved in $25 \mu \mathrm{L}$ PBS. Both solutions were mixed under agitation for $10 \mathrm{~min}$ at room temperature, and then $200 \mu \mathrm{L}$ of $20 \mathrm{mg} / \mathrm{mL}$ collagen solution was added, followed by vortexing for $1 \mathrm{~min}$. Mixed solutions were loaded into Millicell ${ }^{\circledR}$ Cell culture inserts (Millipore, Billerica, MA, USA), and the inserts were placed in a 12 -well plate and incubated at $37^{\circ} \mathrm{C}$ for $30 \mathrm{~min}$. Next, $1 \mathrm{~mL}$ of PBS was added to each well, and the plate was incubated at $37^{\circ} \mathrm{C}$ with shaking at $80 \mathrm{rpm}$. Samples released from the inserts were collected at each time point, and $1 \mathrm{~mL}$ of fresh PBS was added. Collected samples were frozen until analysis. To measure the release profile of encapsulated Dox and GM-CSF at elevated temperature, an NIR laser was used to illuminate the collagen $/ \gamma$-PGA hydrogel until the temperature of the hydrogel had increased to approximately $42^{\circ} \mathrm{C}$. The released Dox was quantified using a ultraviolet-visible (UV-vis) spectrophotometer (UV-1800, Shimadzu Corp., Kyoto, Japan), analyzed at 495 nm, and GM-CSF was quantified using Mouse GM-CSF ELISA set (BD Biosciences, Franklin Lakes, NJ, USA).

\section{In vitro and in vivo photothermal-modulated magnetic relaxation in collagen $/ \gamma-\mathrm{PGA} / \mathrm{MnFe}_{2} \mathrm{O}_{4}$ hydrogels}

Manganese-doped superparamagnetic iron oxide nanoparticles $\left(\mathrm{MnFe}_{2} \mathrm{O}_{4}\right)$ were first synthesized by the thermal decomposition method as described previously. ${ }^{27}$ To prepare $\gamma$-PGA coated $\mathrm{MnFe}_{2} \mathrm{O}_{4}$ nanoparticles, the $\mathrm{MnFe}_{2} \mathrm{O}_{4}$ nanoparticle suspension in chloroform $(100 \mathrm{mg} / 10 \mathrm{~mL})$ was mixed with $\gamma$-PGA in DMSO $(100 \mathrm{mg} / 10 \mathrm{~mL})$. The mixture was stirred at $60^{\circ} \mathrm{C}$ for $2 \mathrm{~h}$. After the reaction, the solution was cooled to room temperature and washed by centrifugation with a cosolvent (ethanol, chloroform, and hexane, 1:1:2) to eliminate unreacted reagents. $\gamma$-PGA-coated $\mathrm{MnFe}_{2} \mathrm{O}_{4}$ nanoparticles obtained as black pellets were placed in vacuum desiccators overnight after removal of the cosolvent. Collagen $/ \gamma$-PGA/ $\mathrm{MnFe}_{2} \mathrm{O}_{4}$ solution was prepared by mixing collagen and $\gamma$-PGA solution containing $\mathrm{MnFe}_{2} \mathrm{O}_{4}$ nanoparticles (volume ratio 4:1). Magnetic resonance (MR) imaging experiments of the collagen $/ \gamma$-PGA/ $\mathrm{MnFe}_{2} \mathrm{O}_{4}$ hydrogel were performed on a $600 \mathrm{MHz}$ (14 T) Bruker nuclear magnetic resonance (NMR) spectrometer (Avance DMX600, Bruker, Billerica, MA, USA) equipped with a triple-gradient system for microscopic imaging. The maximum gradient strength was $200 \mathrm{G} / \mathrm{cm}$, and a 5-mm double-tuned radiofrequency coil was used. For MR spectral measurement of the collagen $/ \gamma-\mathrm{PGA} / \mathrm{MnFe}_{2} \mathrm{O}_{4}$ hydrogel, the hydrogel was placed in standard Wilmad 5-mm NMR tubes. To differentiate collagen $/ \gamma-\mathrm{PGA} / \mathrm{MnFe}_{2} \mathrm{O}_{4}$ hydrogel MR image, we designed a special device for sample filling: one $1.9-\mathrm{mm}$ (inner diameter $=1.5 \mathrm{~mm}$ ) capillary tube was inserted into a standard Wilmad 5-mm NMR tube. In each experiment, one NMR tube was filled with collagen $/ \gamma$-PGA/ $\mathrm{MnFe}_{2} \mathrm{O}_{4}$ hydrogel, while another capillary tube was filled with collagen $/ \gamma$-PGA hydrogel. To confirm the photothermalmodulated change of the MR image and relaxation time in vivo, collagen $/ \gamma$-PGA/ICG/ $\mathrm{MnFe}_{2} \mathrm{O}_{4}$ hydrogels $(100 \mu \mathrm{L})$ were injected subcutaneously into left and right hind legs of female BALB/c nude mice (6-7 weeks old). One hour after injection of collagen $/ \gamma$-PGA/ICG/ $\mathrm{MnFe}_{2} \mathrm{O}_{4}$ hydrogels, only the left side was irradiated with the NIR laser $\left(0.63 \mathrm{~W} / \mathrm{cm}^{2}\right.$, $3 \mathrm{~min}$ ). For MR imaging, the mouse was placed inside the MR coil. The mouse was anesthetized with $4 \%(\mathrm{v} / \mathrm{v})$ isoflurane $/ \mathrm{O}_{2}$ and maintained in a $1 \%-2 \%(\mathrm{v} / \mathrm{v})$ isoflurane $/ \mathrm{O}_{2}$ atmosphere during the experiments. T2-weighted MR images and T2 relaxation times of mice injected with collagen $/ \gamma-\mathrm{PGA} / \mathrm{ICG} /$ $\mathrm{MnFe}_{2} \mathrm{O}_{4}$ hydrogel were obtained using a Bruker Biospin 4.7 $\mathrm{T}$ scanner with a quadrature birdcage radiofrequency coil (35 mm inner diameter, Bruker).

\section{Results and discussion Characterization of collagen $/ \gamma-$ PGA hydrogels}

When $\gamma$-PGA was mixed with a high concentration of collagen $(20 \mathrm{mg} / \mathrm{mL})$ at room temperature $\left(25^{\circ} \mathrm{C}\right)$, highly viscous and transparent collagen solution was changed to a low viscous and turbid solution (Figure 1A and B). This suggests that a new complex structure was generated by the molecular interaction between collagen and $\gamma$-PGA. However, the collagen $/ \gamma$-PGA mixture remained in the sol state at $25^{\circ} \mathrm{C}$. In contrast, when the temperature was increased to body temperature $\left(37^{\circ} \mathrm{C}\right)$, the viscosity of the collagen $/ \gamma$-PGA mixture was dramatically increased, suggesting that a gel structure had been formed (Figure 1B). As for the ratio of collagen and $\gamma$-PGA, when the mass ratio of $\gamma$-PGA was less than $20 \%$, the viscosity decrease effect was insignificant, and when it was more than $20 \%$, the gelation did not occur. In a temperature sweep, the elastic modulus of a collagen $/ \gamma$-PGA hydrogel showed a drastic increase up to $130 \mathrm{~Pa}$ between $35^{\circ} \mathrm{C}$ and $42^{\circ} \mathrm{C}$, which suggested the phase transition from sol to gel, while it was decreased rapidly at more than $42^{\circ} \mathrm{C}$, which suggested the breakup of the formed gel (Figure S1). As the temperature was increased to greater than $42^{\circ} \mathrm{C}$, the hydrogel structure began to break into turbid sols and then 
A
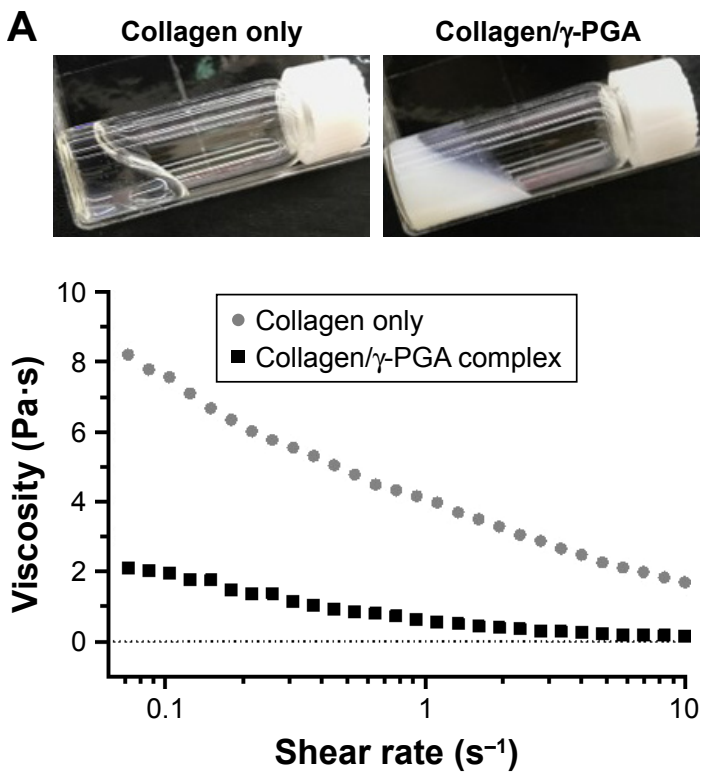

B
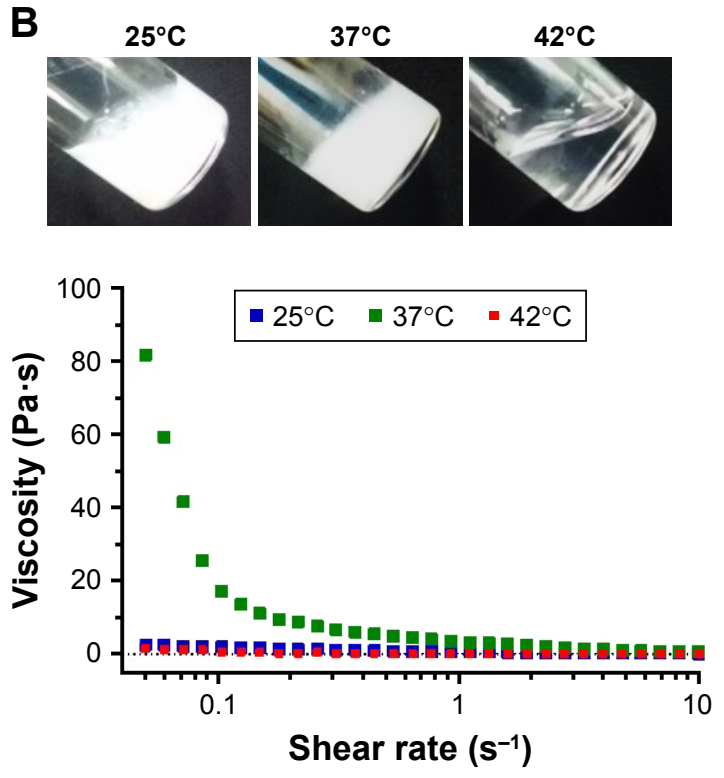

Figure I Rheological properties of collagen $/ \gamma$-PGA hydrogel.

Notes: (A) Viscosities and photographs of collagen only and collagen $/ \gamma$-PGA complex at $25^{\circ} \mathrm{C}$. (B) Viscosities and photographs of collagen $/ \gamma-\mathrm{PGA}$ complex at $25^{\circ} \mathrm{C}, 37^{\circ} \mathrm{C}$, and $42^{\circ} \mathrm{C}$.

Abbreviation: $\gamma$-PGA, poly $(\gamma$-glutamic acid).

transparent sols again (Figure 1B). These results suggest that the intermolecular hydrogen bond interactions between triple helices in collagen were completely disrupted, and the collagen gel structure could not sustain the gel structure at $42^{\circ} \mathrm{C} \cdot{ }^{16,17}$ In fact, collagens are known to form highly viscous solutions via strong hydrogen bonding interactions between triple helices in addition to water-mediated hydrogen bonding between water molecules and the triple helices. ${ }^{16,17}$ To investigate the role of hydrogen bonding interaction in the gelation of collagen hydrogel, we used urea as a hydrogen bonding inhibitor. ${ }^{28,29}$ In the presence of high urea concentrations, the collagen $/ \gamma$-PGA hydrogel began to break down and became transparent even at body temperature (Figure 2). These results suggest that urea inhibited hydrogen bonding interactions in hydrogels. When $\gamma$-PGA was mixed with collagens, $\gamma$-PGA could also act as an inhibitor of the hydrogen bonding interactions between triple helices. The abundant carboxylate groups as well as carbonyl and nitrogen moieties in the amide linkage of $\gamma$-PGA may interact with triple helix chains via hydrogen bonding interactions. When $\gamma$-PGA having high viscosity was added into the collagen, the viscosity of the mixture should be increased if there is no special interaction between collagen and $\gamma$-PGA. However, the viscosity of the mixture was drastically reduced, suggesting the strong interaction between two materials and formation of a new structure. Because $\gamma$-PGA has a lot of carboxyl, amide, and carbonyl groups, they can bind with triple helix of collagen by hydrogen bond interaction..$^{30-32}$ Therefore, the viscosity of the collagen solution was dramatically reduced upon addition of $\gamma$-PGA (Figure 1A). Furthermore, $\gamma$-PGA could also absorb a large number of water molecules because of the abundant carboxylate groups. ${ }^{33}$ The highly porous gel structure of collagen/ $\gamma$-PGA hydrogels, which was not observed in conventional collagen hydrogels, suggests that strong interactions occur between $\gamma$-PGA and water molecules (Figure 3). The pores in the hydrogels indicate the location of water molecules before freeze-drying of the hydrogel solutions. These results suggest that the intrinsic gelation character of high concentration collagen solutions can be modified to exhibit a low viscous sol state at room temperature and nonflowing gel state at approximately body temperature by introducing $\gamma$-PGA. As mentioned, the gelation behavior in collagen $/ \gamma-\mathrm{PGA}$ hydrogels is related to the electrostatic interactions between cationic collagen and anionic $\gamma$-PGA in addition to the hydrogen bond interactions between them.

\section{Photothermal effect on collagen/ $\gamma-P G A /$ ICG hydrogels}

As observed previously for the temperature-dependent phase transition behavior of the collagen/ $\gamma$-PGA complex, distinct phase transitions were detected in two temperature ranges. Although the collagen $/ \gamma$-PGA complex is a free-flowing sol at ambient temperature, the complex is converted into a nonflowing gel at physiological temperature upon injection into body, which can serve as a sustained delivery depot 


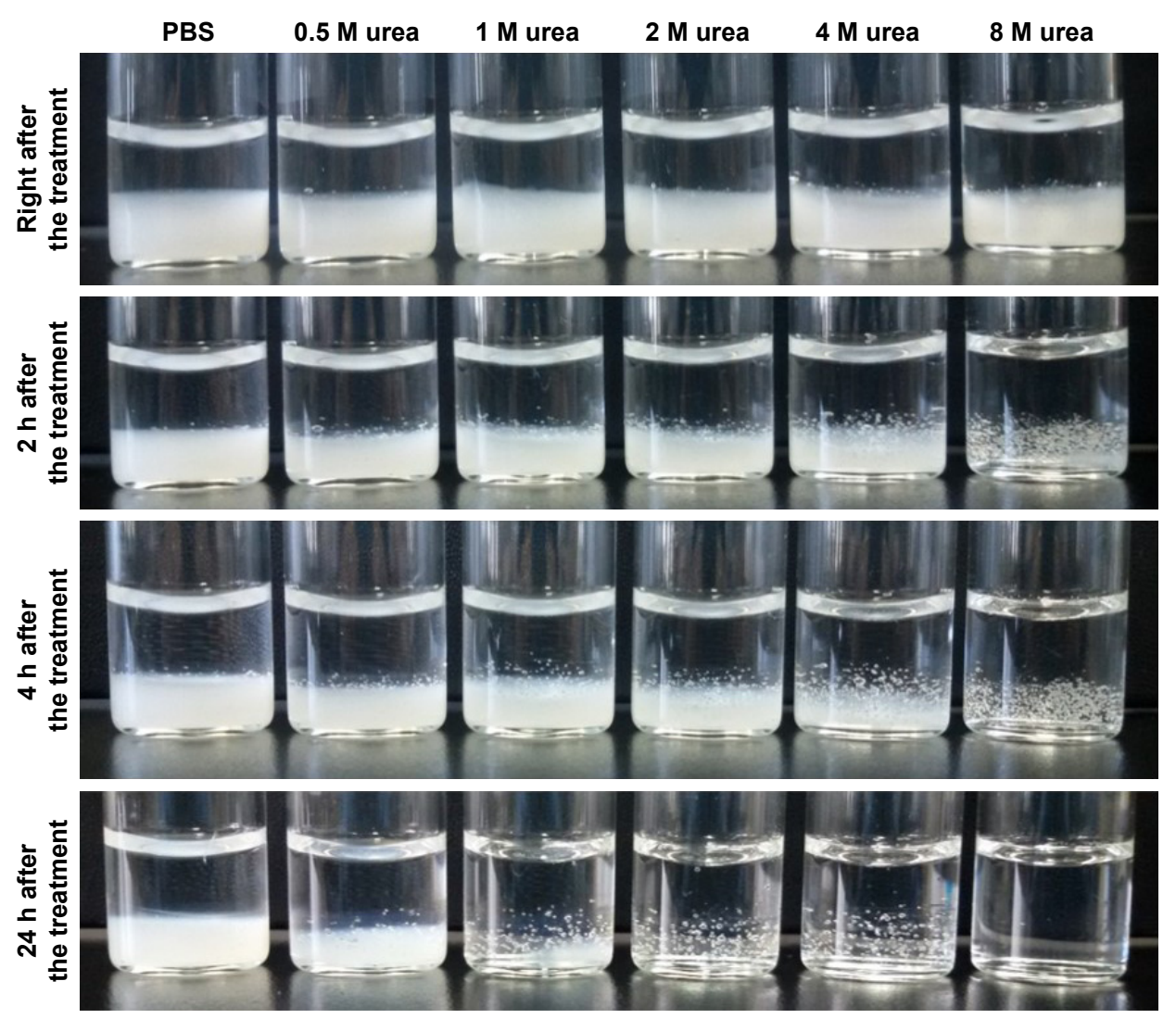

Figure 2 Effect of different concentrations of urea (hydrogen bonding inhibitor) on stability of collagen/ $\gamma$-PGA hydrogels.

Note: Stability of collagen $/ \gamma$-PGA hydrogels was measured at ambient temperature.

Abbreviations: $\gamma$-PGA, poly $(\gamma$-glutamic acid); PBS, phosphate-buffered saline.

in vivo. As the temperature is increased up to $42^{\circ} \mathrm{C}$, the hydrogel structure began to break into turbid sols followed by transparent sols. Because the 1 st and 2 nd transitions occurred at approximately $37^{\circ} \mathrm{C}$ (body temperature) and $42^{\circ} \mathrm{C}$ (cell death), the injectable hydrogel can be designed to form an in situ gel at body temperature and release encapsulated drugs in a controlled manner. At $42^{\circ} \mathrm{C}$, the so-called "hyperthermia" effect can be used as a combined cancer therapeutic strategy. ${ }^{34,35}$ At this temperature, cancer cells begin to die because of apoptosis or necrosis, which can be accelerated by a burst release of encapsulated anticancer drugs during destruction of the hydrogel structure. To test the feasibility of this photothermal effect, collagen $/ \gamma$-PGA hydrogel containing ICG, an NIR light-absorbing dye widely used in human clinics as an NIR imaging contrast agent and phototherapeutic drug, was fabricated. ${ }^{36-38}$ When an NIR laser
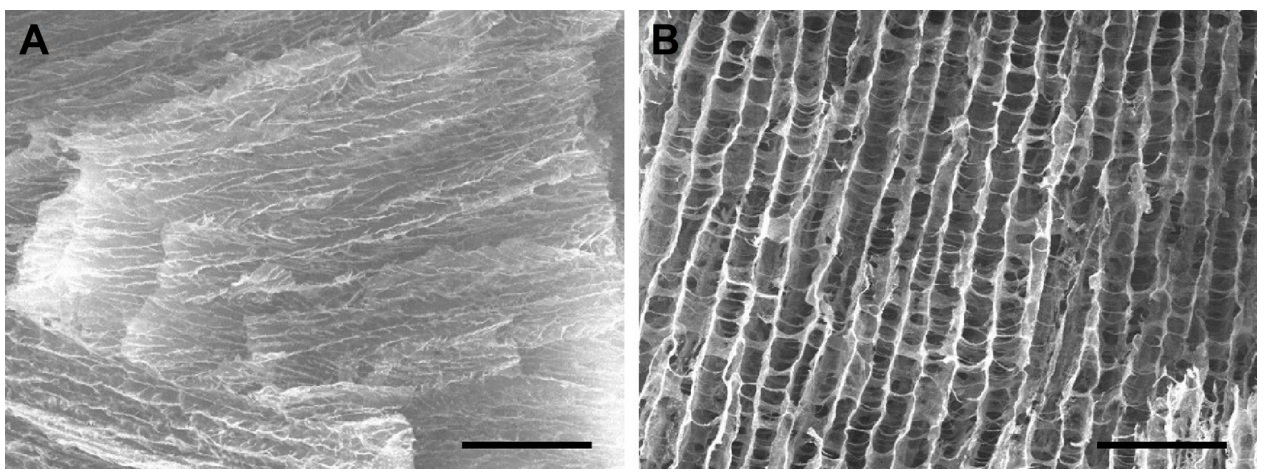

Figure 3 SEM images of (A) collagen only and (B) collagen $/ \gamma-P G A$ hydrogels after gelation at $37^{\circ} \mathrm{C}$ for $30 \mathrm{~min}$.

Notes: Scale bar represents $100 \mu \mathrm{m}$. Magnification $\times 250$.

Abbreviations: SEM, scanning electron microscopy; $\gamma$-PGA, poly $\gamma$-glutamic acid). 
$(\lambda=785 \mathrm{~nm})$ was illuminated on collagen $/ \gamma$-PGA/ICG hydrogel at body temperature, the illuminated core was changed into transparent sol because the ICG strongly absorbed NIR light, and the absorbed light energy was converted into heat, which increased the temperature of the illuminated region and induced a phase transition (Figure 4). When the hydrogel was injected into mice and an NIR laser was applied for illumination, an NIR fluorescence signal was also generated (Figures 4 and S2). These results suggest that the in situ formed hydrogel structure was disrupted at approximately $42^{\circ} \mathrm{C}$ and encapsulated ICG was released over time. Because the concentration of ICG in the core of hydrogel was very high before NIR heating, a weak NIR fluorescence signal was generated via self-quenching. However, heating of the hydrogel can accelerate the release of encapsulated ICG, and the quenched NIR signal recovers over time. ${ }^{39}$ When we measured the temperature change of collagen $/ \gamma$-PGA/ ICG hydrogels having various concentration of ICG with irradiation of NIR laser, the temperature increase was highly dependent on the concentration of ICG. When the concentration of ICG was $10 \mu \mathrm{g} / \mathrm{mL}$, the temperature increase was very slow and could not reach around $42^{\circ} \mathrm{C}$ even after 3 min irradiation, but when the concentration of ICG was $200 \mu \mathrm{g} / \mathrm{mL}$, the temperature increase rate was too fast and it was not easy to control the temperature change in a systematic way (Figure S3). Therefore, hydrogels were prepared at ICG concentration of $100 \mu \mathrm{g} / \mathrm{mL}$ for the photothermal-modulated drug delivery and magnetic relaxation. We also investigated the effect of ICG concentration on the increase in body temperature after the collagen $/ \gamma$-PGA/ICG hydrogel was injected into mice. As shown in Figures 5 and S4, the temperature increase was dependent on the ICG concentration in the hydrogel. While there was no temperature increase in mice injected with collagen/ $\gamma$-PGA hydrogel alone, the temperature was increased from $36.7^{\circ} \mathrm{C}$ to $48.1^{\circ} \mathrm{C}$ after 5 min NIR laser illumination in mice injected with collagen/ $\gamma$-PGA/ICG hydrogel (100 $\mu$ g of ICG). These results suggest that a temperature-responsive phase transition behavior of collagen $/ \gamma$-PGA hydrogel can be achieved and modulated using NIR light based on the photothermal effect.

\section{Photothermal-modulated delivery of Dox and GM-CSF by collagen/ $\gamma$-PGA/ICG hydrogels}

Based on the experimental results of the photomodulated phase transition, an injectable collagen $/ \gamma$-PGA hydrogel can be designed to deliver therapeutic agents at predetermined rates to achieve a desirable, effective drug concentration during a specified time. We investigated whether the hydrogel could be used for the on-demand release of anticancer drugs in a spatiotemporally controlled manner. We used Dox, a model anticancer drug, to evaluate the release characteristics of the collagen $\gamma$-PGA hydrogel before and after NIR laser treatment. As shown in Figure 6A, Dox release was
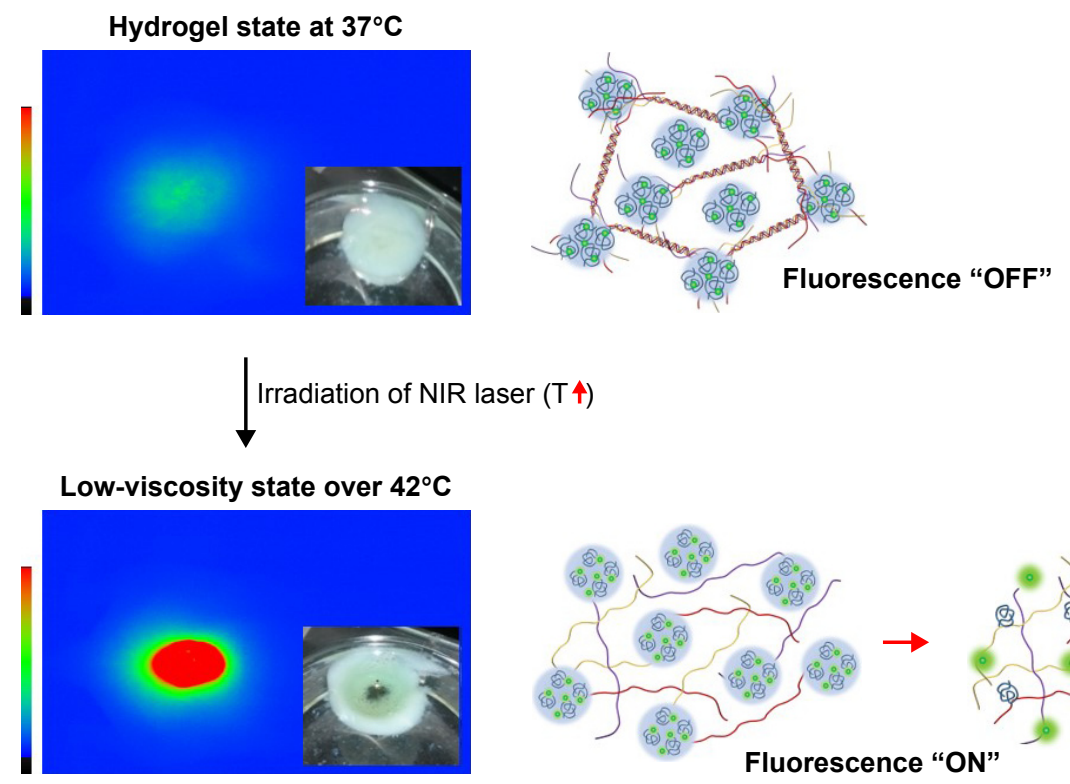

Figure 4 Fluorescence recovery of ICG in collagen/ $\gamma$-PGA/ICG hydrogels after irradiation with NIR laser.

Notes: The inset of the left panel is a photograph of collagen/ $\gamma-P G A / I C G$ (collagen/ $\gamma-P G A$ hydrogels containing ICG) before and after irradiation with an NIR laser. Right panel is schematic illustration of mechanism of fluorescence recovery of ICG in collagen/ $\gamma$-PGA/ICG hydrogels after irradiation with an NIR laser.

Abbreviations: ICG, indocyanine green; $\gamma$-PGA, poly $(\gamma$-glutamic acid); NIR, near-infrared; T, temperature. 

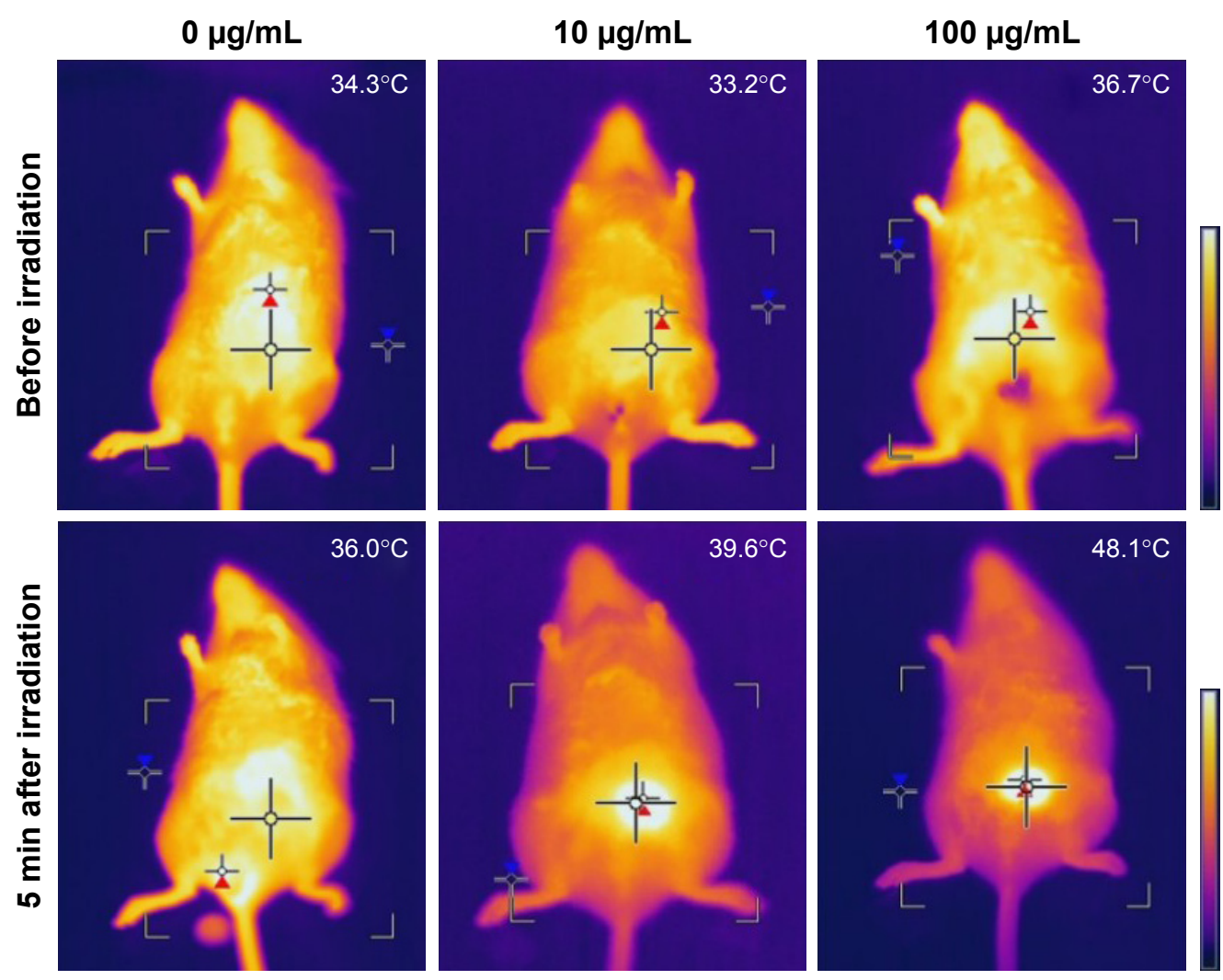

Figure 5 In vivo temperature change in mice injected with collagen/ $\gamma-P G A / I C G$ hydrogel after irradiation with an NIR laser.

Notes: Temperature in mice injected with collagen/ $\gamma$-PGA/ICG hydrogels before and after irradiation with an NIR laser. The concentrations of ICG in the hydrogels were 0,10 , and $100 \mu \mathrm{g} / \mathrm{mL}$ respectively.

Abbreviations: $\gamma$-PGA, poly $(\gamma$-glutamic acid); ICG, indocyanine green; NIR, near-infrared.

very slow and only $18 \%$ of encapsulated drug was released even after 4 days. Because Dox has a cationic charge, it can bind strongly to the anionic $\gamma$-PGA of the hydrogel via electrostatic interactions, and so the release of Dox in the hydrogel can be retarded. However, when NIR laser was used to illuminate the collagen/ $\gamma-\mathrm{PGA} /$ Dox hydrogel, the rate of Dox release was increased, which is related to the loose structure of the hydrogel induced by the phase transition. As a model protein drug, GM-CSF was also encapsulated in the collagen $/ \gamma$-PGA hydrogel. GM-CSF, which is a cytokine produced by a variety of immune cells including T-cells, macrophages, endothelial cells, and fibroblasts upon receiving an immune stimulus, has been widely used as immune modulator. ${ }^{40}$ The release of encapsulated GM-CSF protein
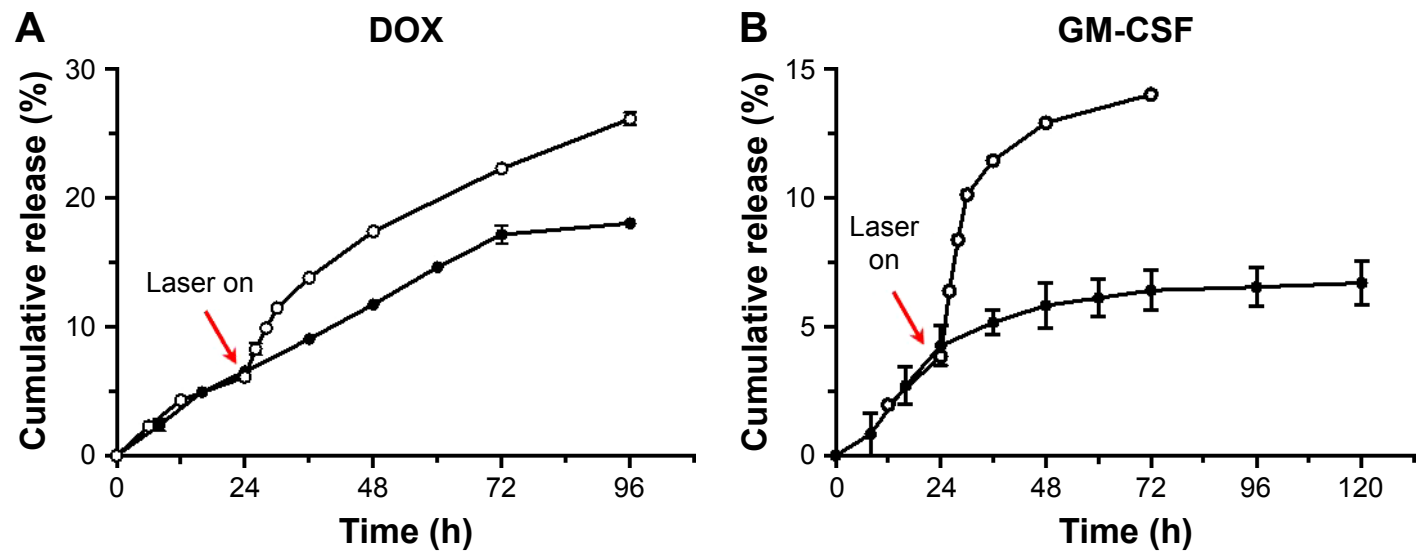

Figure 6 Photothermal-modulated release profile of (A) Dox and (B) GM-CSF from collagen/ $\gamma$-PGA hydrogel.

Note: $\bullet=$ release profile at $37^{\circ} \mathrm{C}, \circ=$ release profile after photothermal treatment.

Abbreviations: Dox, doxorubicin; GM-CSF, granulocyte-macrophage colony-stimulating factor; $\gamma$-PGA, poly $(\gamma$-glutamic acid). 
was also increased after illumination with the NIR laser (Figure 6B). Based on these results, the collagen $/ \gamma-\mathrm{PGA} / \mathrm{GM}-$ CSF hydrogel can be used as an immune priming center to recruit immune cells and tailor the body's immune response. ${ }^{41}$ In the future, these results can be extended for combination cancer therapy, in which NIR light can be used to illuminate hydrogel-containing therapeutic drugs in order to increase both the temperature of collagen $/ \gamma$-PGA hydrogel up to $42^{\circ} \mathrm{C}$ to destruct tumor cells through hyperthermia and induce the release of loaded anticancer drugs into tumor cells.

\section{Photothermal-modulated magnetic relaxation in collagen/ $\gamma-P G A / I C G /$ $\mathrm{MnFe}_{2} \mathrm{O}_{4}$ hydrogels}

We also investigated whether the photoresponsive collagen/ $\gamma$-PGA hydrogel can be used for in vivo monitoring of the phase transition using molecular imaging technology such as magnetic resonance imaging (MRI). Because MRI provides a high-resolution image and soft tissue contrast without requiring radiation exposure, this method is considered an excellent imaging tool for noninvasive in vivo imaging. ${ }^{42-46}$ To fabricate hydrogels containing magnetic nanoparticles as MRI contrast agents, we synthesized $\mathrm{MnFe}_{2} \mathrm{O}_{4}$ nanoparticles in organic solvents and transferred the hydrophobic $\mathrm{MnFe}_{2} \mathrm{O}_{4}$ nanoparticles into aqueous solutions using anionic-charged $\gamma$-PGA. ${ }^{27}$ The $\gamma$-PGA-coated $\mathrm{MnFe}_{2} \mathrm{O}_{4}$ nanoparticles were used for hydrogel formation by complexing with collagen as described above.
As shown in Figure 7A, the collagen $/ \gamma$-PGA hydrogels containing $\mathrm{MnFe}_{2} \mathrm{O}_{4}$ nanoparticles (collagen $/ \gamma-\mathrm{PGA} / \mathrm{MnFe}_{2} \mathrm{O}_{4}$ ) exhibited similar phase transition behavior as shown in Figure 1. When the temperature of NMR tubes containing collagen $/ \gamma$-PGA hydrogels (inner tube) and collagen $/ \gamma$-PGA/ $\mathrm{MnFe}_{2} \mathrm{O}_{4}$ (outer tube) was changed, T2 brightening effect was observed in the outer tube, while there was no change in the inner tube (Figure 7B). The T2 relaxation time of collagen/ $\gamma$-PGA/ $\mathrm{MnFe}_{2} \mathrm{O}_{4}$ was changed from $32.44 \mathrm{~ms}\left(25^{\circ} \mathrm{C}\right)$ to $29.95 \mathrm{~ms}\left(37^{\circ} \mathrm{C}\right)$ as well as from $29.95 \mathrm{~ms}\left(37^{\circ} \mathrm{C}\right)$ to $36.37 \mathrm{~ms}$ $\left(42^{\circ} \mathrm{C}\right)$. Because the distance between $\mathrm{MnFe}_{2} \mathrm{O}_{4}$ nanoparticles is increased during the phase transition from the gel state to the sol state, the magnetic relaxation value was changed and $\mathrm{T} 2$ relaxation time was increased, inducing $\mathrm{T} 2$ brightening when the temperature was increased from $37^{\circ} \mathrm{C}$ to $42^{\circ} \mathrm{C}$ (Figure 7C). ${ }^{42,43}$ Following these in vitro experiments, we investigated whether the same effect occurred in vivo. When NIR laser was illuminated on the injected collagen $/ \gamma$-PGA/ ICG/ $\mathrm{MnFe}_{2} \mathrm{O}_{4}$ hydrogels, T2 brightening was also observed, while no MR signal change was observed in hydrogels not treated with an NIR laser (Figure 8A). The T2 relaxation time of hydrogels illuminated with the NIR laser changed from $43.59 \mathrm{~ms}\left(37^{\circ} \mathrm{C}\right)$ to $57.96 \mathrm{~ms}\left(42^{\circ} \mathrm{C}\right)$ (Figure $\left.8 \mathrm{~B}\right)$. These results suggest that collagen $/ \gamma$-PGA hydrogels can be used for photomodulated delivery of anticancer drugs, and the phase transition behavior in vivo can be monitored by magnetic relaxation changes. Notably, the collagen $/ \gamma$-PGA hydrogel is

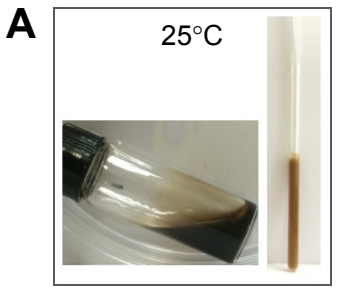

C

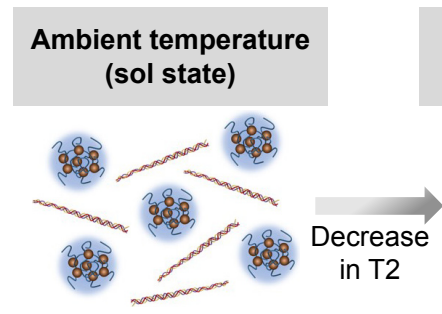

High T2
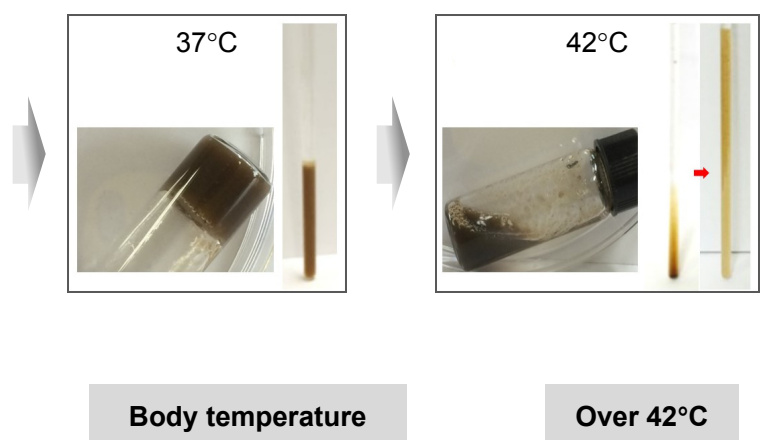
(gel state)

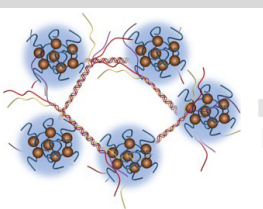

Low T2
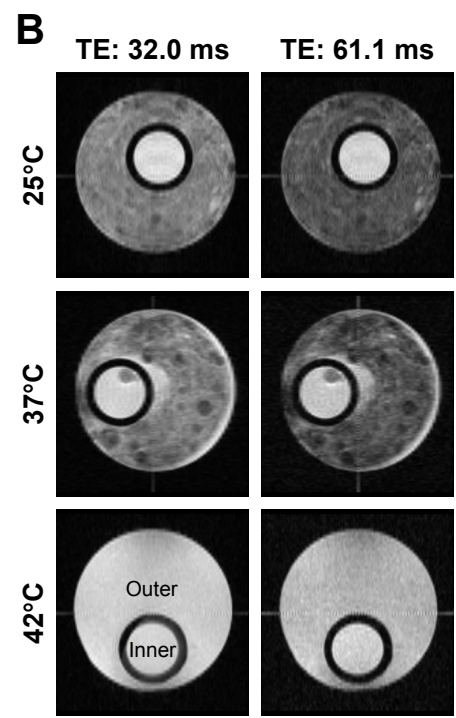

Figure 7 Phase transition and change in MR properties of collagen $/ \gamma-\mathrm{PGA} / \mathrm{MnFe}_{2} \mathrm{O}_{4}$ hydrogels

Notes: (A) Photographs of phase transition for collagen $/ \gamma-\mathrm{PGA} / \mathrm{MnFe}_{2} \mathrm{O}_{4}$ hydrogel. Photographs were obtained in vials and NMR tubes. (B) Resonance-selective discrimination of $\mathrm{MR}$ images for collagen $/ \gamma-\mathrm{PGA}$ and collagen $/ \gamma-\mathrm{PGA} / \mathrm{MnFe}_{2} \mathrm{O}_{4}$ hydrogels with temperature increase. Inner area indicates collagen $/ \gamma-\mathrm{PGA}$ hydrogel without $\mathrm{MnFe} \mathrm{O}_{4}$ and outer area indicates collagen/ $\gamma-\mathrm{PGA} / \mathrm{MnFe}_{2} \mathrm{O}_{4}$ hydrogel. MR imaging experiment was performed on a $600 \mathrm{MHz} \mathrm{NMR}$ spectrometer. (C) Schematic illustration of the change in $\mathrm{T} 2$ relaxation time due to phase transition of collagen $/ \gamma-\mathrm{PGA} / \mathrm{MnFe}_{2} \mathrm{O}_{4}$ hydrogel with temperature increase.

Abbreviations: MR, magnetic resonance; $\gamma$-PGA, poly $(\gamma$-glutamic acid); NMR, nuclear magnetic resonance; TE, echo time. 
A

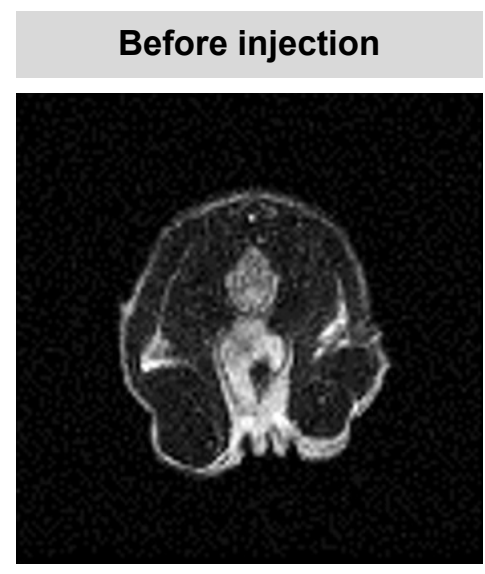

Before injection

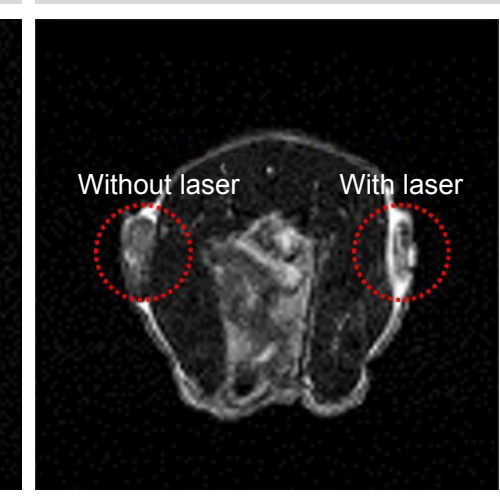

$1 \mathrm{~h}$ after injection of collagen/ $\gamma$-PGA/ICG/MnFe ${ }_{2} \mathrm{O}_{4}$

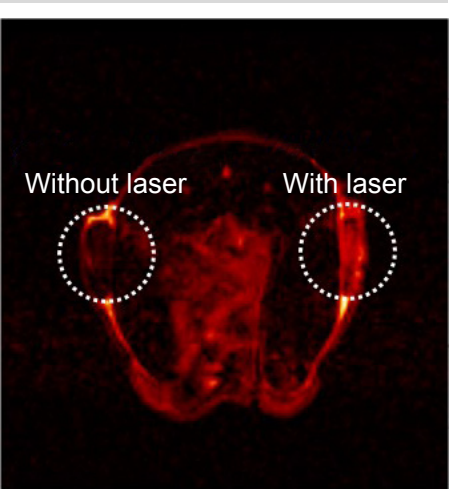

TE: $7.5 \mathrm{~ms}$

B
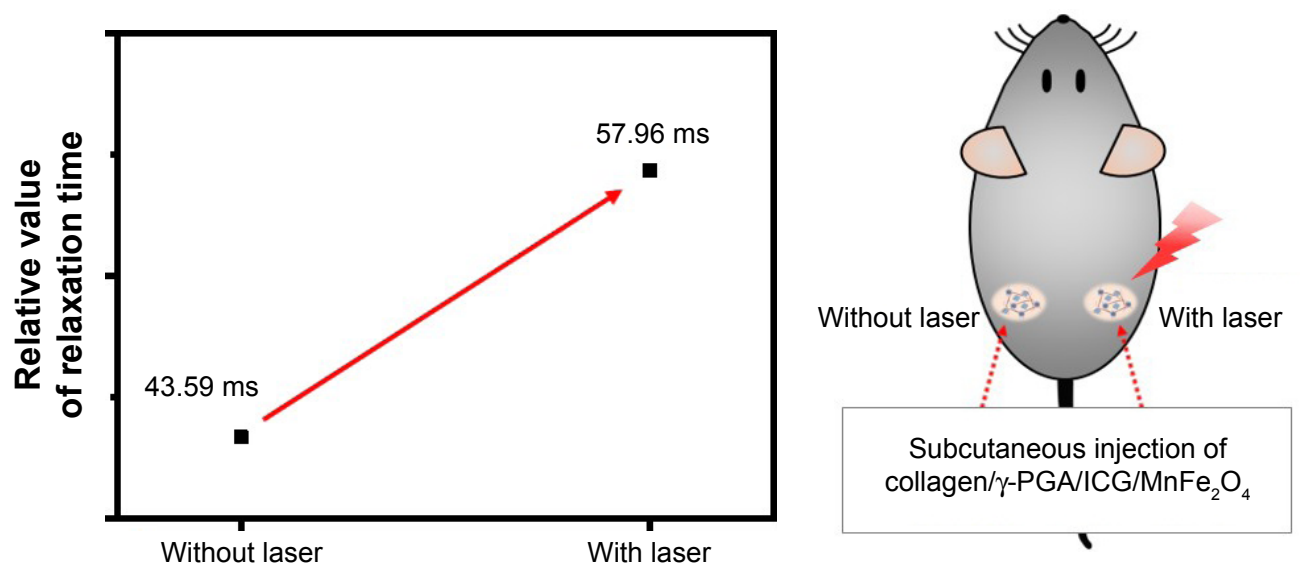

Figure 8 In vivo T2 brightening effect of collagen/ $\gamma$-PGA/ICG/MnFe $\mathrm{O}_{4}$ hydrogels.

Notes: (A) In vivo photothermal-modulated change of MR image for mice injected with collagen/ $\gamma-P G A / I C G / M n F e{ }_{2} \mathrm{O}_{4}$ hydrogels. In each image after injection of hydrogel, left circle area indicates part without NIR laser irradiation and right circle area indicates part with NIR laser irradiation. (B) T2 relaxation time of part injected with collagen/ $\gamma$-PGA/ICG/MnFe $\mathrm{O}_{4}$ hydrogels with or without irradiation of NIR laser.

Abbreviations: $\gamma$-PGA, poly $(\gamma$-glutamic acid); ICG, indocyanine green; MR, magnetic resonance; NIR, near-infrared; TE, echo time.

advantageous from a material regulation perspective because the hydrogel formed via elementary molecular interactions (ie, hydrogen bonding and electrostatic interactions) between bioderived polymers, rather than through chemical crosslinking between synthetic polymers.

\section{Conclusion}

We developed injectable and photoresponsive collagen/ $\gamma$-PGA hydrogels by combining collagen and anionic poly (amino acids), $\gamma$-PGA, and investigated whether these materials could be used for photothermal-modulated drug delivery and magnetic relaxation switching. By taking advantage of the abundant carboxylate groups on $\gamma$-PGA, cationic-charged antitumor drugs and magnetic nanoparticles as MRI contrast agents were successfully loaded into the collagen $/ \gamma$-PGA hydrogels. By increasing the temperature of collagen $/ \gamma-\mathrm{PGA} /$ Dox/ICG/ $\mathrm{MnFe}_{2} \mathrm{O}_{4}$ hydrogels using NIR light, the release of encapsulated anticancer drugs and magnetic relaxation between magnetic nanoparticles were successfully modulated. The injectable and photoresponsive collagen $/ \gamma$-PGA hydrogels developed in this study may be useful for drug delivery, tissue engineering, and cell-based cancer therapy because both the release kinetics of loaded therapeutic components and signal change of molecular imaging probes can be modulated to treat and monitor the microenvironment of the injection site. ${ }^{47-54}$

\section{Acknowledgments}

This work was supported by financial support from the National Research Foundation of Korea (NRF) grant funded by the Korean government (MSIP) (grant no 2012M3A9C6050070, no 2014R1A2A1A10049960, no 2015R1A2A1A15051980) and by a grant from the Korea Health Technology R\&D Project, provided by the Korea Health Industry Development Institute, funded by the Ministry of Health \& Welfare (grant no HI14C2680). 


\section{Disclosure}

The authors report no conflicts of interest in this work.

\section{References}

1. Schmidt JJ, Rowley J, Kong HJ. Hydrogels used for cell-based drug delivery. J Biomed Mater Res A. 2008;87(4):1113-1122.

2. Calo E, Khutoryanskiy VV. Biomedical applications of hydrogels: a review of patents and commercial products. Eur Polym J. 2015;65: 252-267.

3. Conde J, Oliva N, Artzi N. Implantable hydrogel embedded dark-gold nanoswitch as a theranostic probe to sense and overcome cancer multidrug resistance. Proc Natl Acad Sci U S A. 2015;112(11):E1278-E1287.

4. Fakhari A, Subramony JA. Engineered in-situ depot-forming hydrogels for intratumoral drug delivery. $J$ Control Release. 2015;220:465-475.

5. Nguyen QV, Huynh DP, Park JH, Lee DS. Injectable polymeric hydrogels for the delivery of therapeutic agents: a review. Eur Polym J. 2015;72:602-619.

6. Norouzi M, Nazari B, Miller DW. Injectable hydrogel-based drug delivery systems for local cancer therapy. Drug Discov Today. 2016;21(11): 1835-1849.

7. Sepantafar M, Maheronnaghsh R, Mohammadi H, et al. Stem cells and injectable hydrogels: Synergistic therapeutics in myocardial repair. Biotechnol Adv. 2016;34(4):362-379.

8. Sood N, Bhardwaj A, Mehta S, Mehta A. Stimuli-responsive hydrogels in drug delivery and tissue engineering. Drug Deliv. 2016;23(3): 758-780.

9. Wang QM, Wang Q, Teng W. Injectable, degradable, electroactive nanocomposite hydrogels containing conductive polymer nanoparticles for biomedical applications. Int J Nanomed. 2016;11:131-145.

10. Sun JY, Zhao XH, Illeperuma WR, et al. Highly stretchable and tough hydrogels. Nature. 2012;489(7414):133-136.

11. Gasperini L, Mano JF, Reis RL. Natural polymers for the microencapsulation of cells. J R Soc Interface. 2014;11(100):20140817.

12. Kim JK, Kim HJ, Chung JY, Lee JH, Young SB, Kim YH. Natural and synthetic biomaterials for controlled drug delivery. Arch Pharmacal Res. 2014;37(1):60-68.

13. Wolf MT, Dearth CL, Sonnenberg SB, Loboa EG, Badylak SF. Naturally derived and synthetic scaffolds for skeletal muscle reconstruction. Adv Drug Deliv Rev. 2015;84:208-221.

14. H P S AK, Saurabh CK, A S A, et al. A review on chitosan-cellulose blends and nanocellulose reinforced chitosan biocomposites: properties and their applications. Carbohydr Polym. 2016;150:216-226.

15. Pastuszka MK, MacKay JA. Engineering structure and function using thermoresponsive biopolymers. Wires Nanomed Nanobi. 2016;8(1): 123-138.

16. Nagarajan V, Kamitori S, Okuyama K. Structure analysis of a collagenmodel peptide with a (Pro-Hyp-Gly) sequence repeat. J Biochem 1999;125(2):310-318.

17. Zanaboni G, Rossi A, Onana AM, Tenni R. Stability and networks of hydrogen bonds of the collagen triple helical structure: influence of $\mathrm{pH}$ and chaotropic nature of three anions. Matrix Biol. 2000;19(6): 511-520.

18. Woolfson DN. Building fibrous biomaterials from alpha-helical and collagen-like coiled-coil peptides. Biopolymers. 2010;94(1):118-127.

19. Ferreira AM, Gentile P, Chiono V, Ciardelli G. Collagen for bone tissue regeneration. Acta Biomater. 2012;8(9):3191-3200.

20. Luo T, Kiick KL. Collagen-like peptides and peptide-polymer conjugates in the design of assembled materials. Eur Polym J. 2013;49(10): 2998-3009.

21. Brinkman WT, Nagapudi K, Thomas BS, Chaikof EL. Photo-crosslinking of type I collagen gels in the presence of smooth muscle cells: mechanical properties, cell viability, and function. Biomacromolecules. 2003;4(4):890-895.

22. Qi PW, Zhou YY, Wang DL, He ZH, Li ZJ. A new collagen solution with high concentration and collagen native structure perfectly preserved. Rsc Adv. 2015;5(106):87180-87186.
23. Giudici C, Viola M, Tira ME, Forlino A, Tenni R. Molecular stability of chemically modified collagen triple helices. FEBS Lett. 2003; 547(1-3):170-176.

24. Seo JH, Kim CS, Lee SP. Physicochemical properties of poly- $\gamma$-glutamic acid produced by a novel bacillus subtilis HA isolated from cheonggukjang. Prevent Nutr Food Sci. 2008;13(4):354-361.

25. Lee EH, Son WC, Lee SE, Kim BH. Anti-obesity effects of poly-gammaglutamic acid with or without isoflavones on high-fat diet induced obese mice. Biosci Biotechnol Biochem. 2013;77(8):1694-1702.

26. Shin EJ, Sung MJ, Park JH, et al. Poly-gamma-glutamic acid induces apoptosis via reduction of COX-2 expression in TPA-induced HT-29 human colorectal cancer Cells. Int J Mol Sci. 2015;16(4):7577-7586.

27. Kim HM, Lee H, Hong KS, et al. Synthesis and high performance of magnetofluorescent polyelectrolyte nanocomposites as MR/nearinfrared multimodal cellular imaging nanoprobes. ACS Nano. 2011; 5(10):8230-8240

28. Usha R, Ramasami T. Effect of hydrogen-bond-breaking reagent (urea) on the dimensional stability of rat tail tendon (RTT) collagen fiber. J Appl Polym Sci. 2002;84(5):975-982.

29. Zhang N, Liu FF, Dong XY, Sun Y. Molecular insight into the counteraction of trehalose on urea-induced protein denaturation using molecular dynamics simulation. $J$ Phys Chem B. 2012;116(24):7040-7047.

30. Lin WC, Yu DG, Yang MC. Blood compatibility of novel poly(gammaglutamic acid)/polyvinyl alcohol hydrogels. Colloids Surf B Biointerfaces. 2006;47(1):43-49.

31. Bae KC, Park JH, Na AY, et al. Effect of green tea extract/poly-gammaglutamic acid complex in obese type 2 diabetic mice. Diabetes Metab J. 2013;37(3):196-206.

32. Hu W, Feng X, Liu X, et al. Poly(gamma-glutamic acid) modulates the properties of poly(ethylene glycol) hydrogel for biomedical applications. J Biomater Sci Polym Ed. Epub 2016 Oct 02.

33. Zohuriaan-Mehr MJ, Pourjavadi A, Salimi H, Kurdtabar M. Protein- and homo poly(amino acid)-based hydrogels with super-swelling properties. Polym Adv Technol. 2009;20(8):655-671.

34. Sheng GP, Chen Y, Han LJ, et al. Encapsulation of indocyanine green into cell membrane capsules for photothermal cancer therapy. Acta Biomater. 2016;43:251-261

35. Zhang YY, Ang CY, Zhao YL. Polymeric nanocarriers incorporating near-infrared absorbing agents for potent photothermal therapy of cancer. Polym J. 2016;48(5):589-603.

36. Linsley CS, Quach VY, Agrawal G, Hartnett E, Wu BM. Visible light and near-infrared-responsive chromophores for drug delivery-ondemand applications. Drug Deliv Transl Res. 2015;5(6):611-624.

37. Porcu EP, Salis A, Gavini E, Rassu G, Maestri M, Giunchedi P. Indocyanine green delivery systems for tumour detection and treatments. Biotechnol Adv. 2016;34(5):768-789.

38. Wang Y, Wang C, Ding Y, et al. Biomimetic HDL nanoparticle mediated tumor targeted delivery of indocyanine green for enhanced photodynamic therapy. Colloids Surf B Biointerfaces. 2016;148:533-540.

39. Park HS, Cho MY, Noh YW, Hong KS, Lim YT. Contrast agents based on switchable near-infrared fluorescent nanoprobes for highly sensitive optical imaging. Dyes Pigments. 2017;136:583-589.

40. Becher B, Tugues S, Greter M. GM-CSF: from growth factor to central mediator of tissue inflammation. Immunity. 2016;45(5):963-973.

41. Singh A, Qin H, Fernandez I, et al. An injectable synthetic immunepriming center mediates efficient T-cell class switching and T-helper 1 response against B cell lymphoma. J Control Release. 2011; 155(2):184-192.

42. Perez JM, Josephson L, O'Loughlin T, Hogemann D, Weissleder R. Magnetic relaxation switches capable of sensing molecular interactions. Nat Biotechnol. 2002;20(8):816-820.

43. Paquet C, de Haan HW, Leek DM, et al. Clusters of superparamagnetic iron oxide nanoparticles encapsulated in a hydrogel: a particle architecture generating a synergistic enhancement of the $\mathrm{T} 2$ relaxation. $A C S$ Nano. 2011;5(4):3104-3112.

44. Roth BJ. The role of magnetic forces in biology and medicine. Exp Biol Med (Maywood). 2011;236(2):132-137. 
45. Lee H, Shin TH, Cheon J, Weissleder R. Recent developments in magnetic diagnostic systems. Chem Rev. 2015;115(19):10690-10724.

46. Wu AG, Ou P, Zeng LY. Biomedical applications of magnetic nanoparticles. Nano. 2010;5(5):245-270.

47. Wang C, Varshney RR, Wang DA. Therapeutic cell delivery and fate control in hydrogels and hydrogel hybrids. Adv Drug Deliv Rev. 2010;62(7-8):699-710.

48. Deepa G, Thulasidasan AK, Anto RJ, Pillai JJ, Kumar GS. Cross-linked acrylic hydrogel for the controlled delivery of hydrophobic drugs in cancer therapy. Int J Nanomedicine. 2012;7:4077-4088.

49. Jaiswal MK, De M, Chou SS, et al. Thermoresponsive magnetic hydrogels as theranostic nanoconstructs. ACS Appl Mater Interfaces. 2014; 6(9):6237-6247.

50. Nguyen MK, Alsberg E. Bioactive factor delivery strategies from engineered polymer hydrogels for therapeutic medicine. Prog Polym Sci. 2014;39(7):1236-1265.
51. van Duijnhoven SM, Robillard MS, Langereis S, Grull H. Bioresponsive probes for molecular imaging: concepts and in vivo applications. Contrast Media Mol Imaging. 2015;10(4):282-308.

52. Chen X, Liu Z, Parker SG, et al. Light-induced hydrogel based on tumor-targeting mesoporous silica nanoparticles as a theranostic platform for sustained cancer treatment. ACS Appl Mater Interfaces. 2016;8(25):15857-15863.

53. Wang CP, Wang XY, Dong KY, Luo J, Zhang Q, Cheng YY. Injectable and responsively degradable hydrogel for personalized photothermal therapy. Biomaterials. 2016;104:129-137.

54. Zeng C, Shang W, Liang X, et al. Cancer diagnosis and imaging-guided photothermal therapy using a dual-modality nanoparticle. ACS Appl Mater Interfaces. 2016;8(43):29232-29241. 


\section{Supplementary materials}

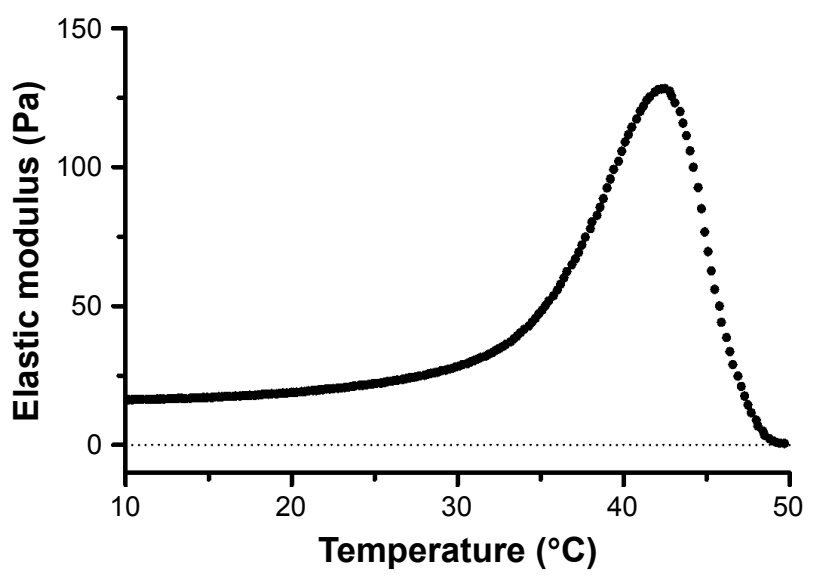

Figure SI Phase transition behavior of collagen/ $\gamma$-PGA hydrogel measured by elastic modulus with temperature sweep.

Notes: Elastic modulus was measured by the oscillatory mode at $1 \mathrm{rad} / \mathrm{sec}$ of frequency with a $2 \%$ constant strain value. The temperature was raised from $10^{\circ} \mathrm{C}$ to $50^{\circ} \mathrm{C}$ at a rate of $2^{\circ} \mathrm{C} / \mathrm{min}$.

Abbreviation: $\gamma$-PGA, poly $(\gamma$-glutamic acid).

A

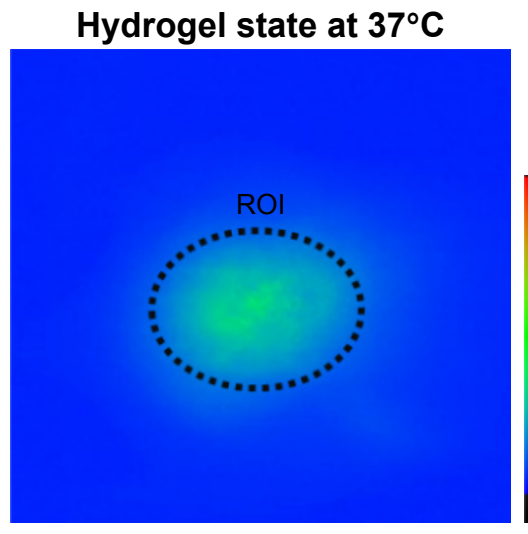

Low-viscosity state over $42^{\circ} \mathrm{C}$

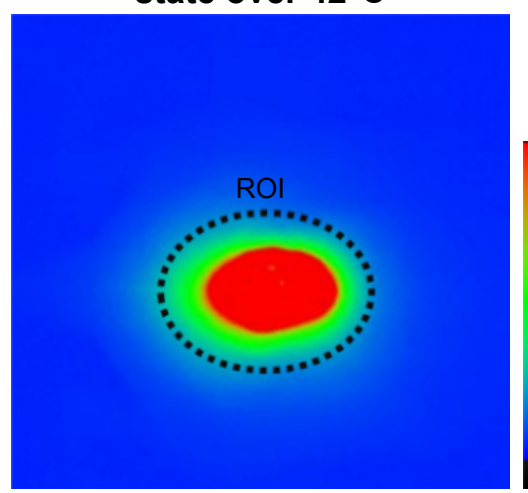

B

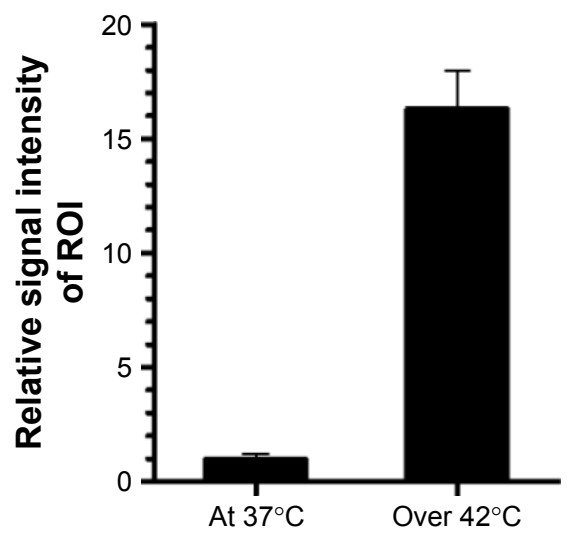

Figure S2 Fluorescence recovery of ICG in collagen/ $\gamma$-PGA/ICG hydrogels according to the phase transition of hydrogel before and after irradiation with an NIR laser. Notes: (A) Representative NIR fluorescence images and (B) relative signal intensity of ROI before (hydrogel state at $37^{\circ} \mathrm{C}$ ) and after (low-viscosity state over $42^{\circ} \mathrm{C}$ ) irradiation with an NIR laser.

Abbreviations: ICG, indocyanine green; $\gamma$-PGA, poly $(\gamma$-glutamic acid); NIR, near-infrared; ROI, region of interest. 


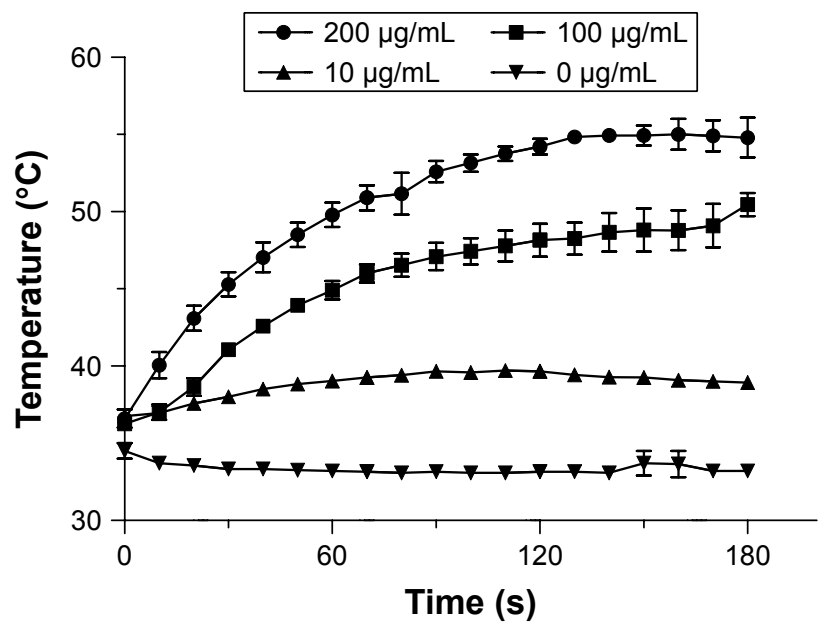

Figure S3 In vitro temperature change in collagen/ $\gamma-\mathrm{PGA} / \mathrm{ICG}$ hydrogel with various concentrations of ICG after irradiation with an NIR laser over time. Note: The concentrations of ICG in the hydrogels were $0,10,100$, and $200 \mu \mathrm{g} / \mathrm{mL}$ respectively.

Abbreviations: $\gamma$-PGA, poly $(\gamma$-glutamic acid); ICG, indocyanine green; NIR, near-infrared.

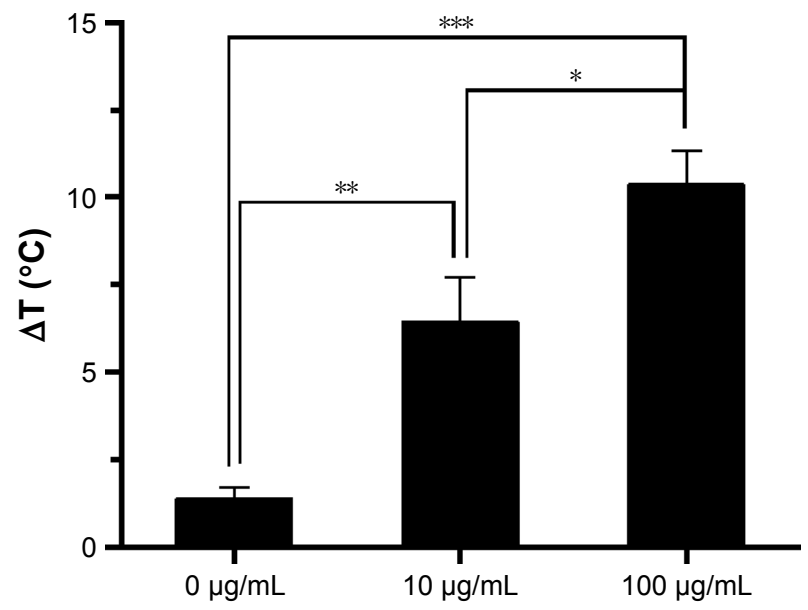

Figure S4 In vivo temperature change in mice injected with collagen/ $\gamma$-PGA/ICG hydrogel after irradiation with an NIR laser.

Notes: Temperature difference $(\Delta \mathrm{T})$ in mice injected with collagen $/ \gamma-\mathrm{PGA} / \mathrm{ICG}$ hydrogels before and after irradiation with an NIR laser. The concentrations of ICG in the hydrogels were 0,10 , and $100 \mu \mathrm{g} / \mathrm{mL}$ respectively. Data are presented as the mean $\pm S D(n=3) . * P<0.05, * * P<0.01, * * * P<0.001$.

Abbreviations: $\gamma$-PGA, poly( $\gamma$-glutamic acid); ICG, indocyanine green; NIR, near-infrared; SD, standard deviation.

\section{Publish your work in this journal}

The International Journal of Nanomedicine is an international, peerreviewed journal focusing on the application of nanotechnology in diagnostics, therapeutics, and drug delivery systems throughout the biomedical field. This journal is indexed on PubMed Central, MedLine, CAS, SciSearch ${ }^{\circledR}$, Current Contents ${ }^{\circledR} /$ Clinical Medicine,
Journal Citation Reports/Science Edition, EMBase, Scopus and the Elsevier Bibliographic databases. The manuscript management system is completely online and includes a very quick and fair peer-review system, which is all easy to use. Visit http://www.dovepress.com/ testimonials.php to read real quotes from published authors. 